\title{
Resposta do feijoeiro ao nitrogênio em cobertura, sob diferentes lâminas de irrigação e preparos do solo(1)
}

\author{
Luis Fernando Stone ${ }^{(2)}$ e José Aloísio Alves Moreira ${ }^{(2)}$
}

\begin{abstract}
Resumo - Em áreas afetadas pelo mofo-branco causado por Sclerotinia sclerotiorum, os produtores têm reduzido a irrigação na fase vegetativa do feijoeiro, para criar condições desfavoráveis à doença. Este trabalho objetivou avaliar o efeito do estresse hídrico, da adubação nitrogenada e do sistema de preparo do solo, na produtividade do feijoeiro. O trabalho foi conduzido em Latossolo VermelhoEscuro, no delineamento em faixas, com parcelas subdivididas, com quatro repetições. As faixas A foram constituídas de cinco lâminas de água, e as faixas B, de três sistemas de preparo do solo: grade aradora, arado de aiveca e plantio direto. Nas subparcelas, foram aplicadas quatro doses de $\mathrm{N}$ em cobertura: 0, 20, 40 e $60 \mathrm{~kg} \mathrm{ha}^{-1}$, nos dois primeiros anos, e $0,40,80$ e $120 \mathrm{~kg} \mathrm{ha}^{-1}$, nos dois últimos. O estresse hídrico na fase vegetativa reduziu a produtividade do feijoeiro. $\mathrm{O}$ aumento na adubação nitrogenada em cobertura compensou, em parte, esta redução. A produtividade sob plantio direto aumentou com o tempo de adoção desta prática. Os sistemas de preparo do solo não afetaram a resposta do feijoeiro ao $\mathrm{N}$
\end{abstract}

Termos para indexação: Phaseolus vulgaris, plantio direto, grade aradora, arado de aiveca, estresse hídrico.

Common bean response to nitrogen topdressing under different irrigation levels and soil tillages

Abstract - In areas affected by white mold caused by Sclerotinia sclerotiorum, common bean growers have reduced the irrigation level during crop vegetative phase in order to create unfavorable conditions to that disease. The objective of this work was to evaluate the effect of water stress, $\mathrm{N}$ application and soil tillage system on common bean yield. The work was carried out on a Dark-Red Latosol, using a splitplot strip block design, with four replications. The A strips consisted of five irrigations levels and the B strips consisted of three soil tillage systems: heavy harrowing, moldboard plowing, and notillage. In the splitplot, four topdress $\mathrm{N}$ levels were applied: $0,20,40$, and $60 \mathrm{~kg} \mathrm{ha}^{-1}$ in the first two years, and $0,40,80$, and $120 \mathrm{~kg} \mathrm{ha}^{-1}$, in the last two. Water stress at vegetative phase decreased common bean yield. Increasing topdressing of $\mathrm{N}$ compensated, in part, this reduction. Common bean yield under no-tillage evolved with time of adoption of this practice. Soil tillage systems did not affect common bean response to $\mathrm{N}$.

Index terms: Phaseolus vulgaris, no-tillage, disk harrow, moldboard plow, water stress.

\section{Introdução}

A irrigação tem forte influência nas doenças causadas por fungos habitantes do solo. O mofo-branco, causado por Sclerotinia sclerotiorum, é favorecido por solos úmidos (Silveira et al., 1996). Weiss et al.

\footnotetext{
(1) Aceito para publicação em 8 de junho de 2000.

(2)Embrapa-Centro Nacional de Pesquisa de Arroz e Feijão, Caixa Postal 179, CEP 75375-000 Santo Antônio de Goiás, GO. Bolsista do CNPq. E-mail: stone@enpaf.embrapa.br, jaloisio@enpaf.embrapa.br
}

(1980) verificaram que, sob irrigação excessiva, a doença foi 13 vezes mais intensa do que sob irrigação normal. Em áreas com problema de mofo-branco, alguns produtores de feijão irrigado têm provocado estresse hídrico na fase vegetativa do ciclo da cultura, reduzindo a lâmina de irrigação. Isto visa criar condições desfavoráveis à doença pela redução da umidade do solo e do desenvolvimento das plantas. Com o desenvolvimento mais lento, a cultura fecha o dossel mais tarde, melhorando a aeração entre as plantas.

Embora a fase reprodutiva seja a mais sensível ao estresse hídrico, o déficit na fase vegetativa também é 
prejudicial (Maurer et al., 1969; Miranda \& Belmar, 1977). Maurer et al. (1969) verificaram que plantas de feijão submetidas a estresse hídrico intenso na fase vegetativa recuperaram-se quando irrigadas adequadamente do início da floração em diante, embora não tenham produzido tão bem quanto aquelas que não sofreram déficit hídrico. Assim, quando não ocorre a doença, a produtividade do feijoeiro pode ser prejudicada por essa prática.

$\mathrm{O}$ incremento na dose de $\mathrm{N}$ aplicada ao feijoeiro compensa parcialmente o efeito do estresse hídrico (Costa, 1986). Esta poderia, portanto, ser uma estratégia para reduzir as perdas em produtividade. Por outro lado, a semeadura direta do feijoeiro irrigado por aspersão na resteva da cultura anterior vem tendo aceitação cada vez maior na Região Central do Brasil. Assim, na resposta do feijoeiro ao $\mathrm{N}$ deve-se considerar o sistema de preparo do solo. Muzilli (1983) relatou maior necessidade de $\mathrm{N}$ no plantio direto, em comparação a outros sistemas de preparo que mobilizam o solo. A principal causa da menor disponibilidade de $\mathrm{N}$ no plantio direto é a imobilização microbiana do fertilizante nitrogenado aplicado em cobertura (Kurihara et al., 1998).

Este trabalho objetivou avaliar o efeito do estresse hídrico, da adubação nitrogenada e do sistema de preparo do solo, na produtividade do feijoeiro.

\section{Material e Métodos}

O trabalho foi conduzido por quatro anos consecutivos com a cultura do feijoeiro, com os ensaios instalados em 23.6.95, 13.6.96, 3.6.97 e 25.5.98, e as colheitas realizadas em 28.9.95, 18.9.96, 8.9.97 e 1.9.98, respectivamente. Os ensaios foram conduzidos em um Latossolo Vermelho-Escuro, de textura argilosa, na Fazenda Capivara, da Embrapa-Centro Nacional de Pesquisa de Arroz e Feijão, localizada no Município de Santo Antônio de Goiás, GO. A análise química inicial do solo $(0-20 \mathrm{~cm})$ apresentou os seguintes resultados: $\mathrm{pH} 5,7 ; \mathrm{Ca}^{2+}, 3,2 \mathrm{cmol}_{\mathrm{c}} \mathrm{dm}^{-3}$; $\mathrm{Mg}^{2+}, 1,4 \mathrm{cmol}_{\mathrm{c}} \mathrm{dm}^{-3} ; \mathrm{Al}^{3+}, 0,1 \mathrm{cmol}_{\mathrm{c}} \mathrm{dm}^{-3} ; \mathrm{P}, 3,6 \mathrm{mg} \mathrm{dm}^{-3}$; $\mathrm{K}, 120 \mathrm{mg} \mathrm{dm}^{-3}$ e $\mathrm{MO}, 18 \mathrm{~g} \mathrm{~kg}^{-1}$. Na estação chuvosa, novembro a abril, a área experimental foi cultivada com milho, em 1994/95 e 1995/96, e com arroz, em 1996/97 e 1997/98. A adubação do milho e do arroz, na semeadura, foi de $400 \mathrm{~kg} \mathrm{ha}^{-1} \mathrm{da}$ fórmula 4-30-16. Em cobertura, foram aplicados, na forma de sulfato de amônio, $60 \mathrm{~kg} \mathrm{ha}^{-1}$ de $\mathrm{N}$ no milho e $70 \mathrm{~kg} \mathrm{ha}^{-1}$ de $\mathrm{N}$ no arroz. Em todos os anos, a adubação na semeadura do feijoeiro foi de
$350 \mathrm{~kg} \mathrm{ha}^{-1}$ da fórmula 4-30-16. A adubação nitrogenada em cobertura, aplicada na quantidade estabelecida para cada tratamento, na forma de sulfato de amônio, foi feita aos 35 dias após a emergência das plântulas do feijoeiro.

Foi utilizado o delineamento em faixas, com parcelas subdivididas, com quatro repetições. As faixas A $(5 \times 27 \mathrm{~m})$, paralelas a uma linha central de aspersores, foram constituídas de cinco lâminas de água, e as faixas $\mathrm{B}$ $(25 \times 9 \mathrm{~m})$, transversais a esta linha, de três sistemas de preparo do solo: plantio direto, aração com grade aradora, e aração com arado de aiveca. Nos sistemas em que foi feita a aração, foram realizadas gradagens niveladoras. No tratamento de plantio direto, foi aplicado, antes da semeadura, o herbicida dessecante glifosate $\left(1,92 \mathrm{~kg} \mathrm{ha}^{-1}\right)$. As parcelas, formadas pela combinação das faixas A e B, foram divididas, e em cada subparcela $(5 \times 2,25 \mathrm{~m})$ foi aplicada uma dose de adubação nitrogenada em cobertura: $0,20,40$ e $60 \mathrm{~kg} \mathrm{ha}^{-1} \mathrm{de} \mathrm{N}$, nos dois primeiros anos, e $0,40,80$ e $120 \mathrm{~kg} \mathrm{ha}^{-1}$, nos dois últimos. A cultivar de feijão utilizada foi a Aporé, semeada a $0,45 \mathrm{~m}$ entre linhas, com 15 sementes por metro.

As diferentes lâminas de água foram fornecidas dos 10 aos 35 dias após a emergência da cultura, mediante a utilização de uma linha de aspersores localizada no meio da área experimental. Antes e após este período, a irrigação foi uniforme em toda a área. A irrigação foi realizada por um sistema convencional de aspersão, constituído de tubos de alumínio com quatro polegadas de diâmetro, e de dois aspersores tipo canhão, modelo $\mathrm{ZN} \mathrm{30,} \mathrm{com} \mathrm{raio} \mathrm{de}$ alcance de $33 \mathrm{~m}$ e precipitação de $19 \mathrm{~mm} \mathrm{~h}^{-1}$, na pressão de serviço de $0,3 \mathrm{MPa}$, dispostos no campo no espaçamento de $36 \times 36 \mathrm{~m}$.

Considerando que a faixa mais próxima da linha central recebeu a lâmina 1 de água, o controle da irrigação foi realizado na faixa subseqüente, que recebeu a lâmina 2 de água. Nesta faixa, a irrigação foi conduzida de maneira que a tensão da água do solo, medida a $0,15 \mathrm{~m}$ de profundidade, não ultrapassasse $0,03 \mathrm{MPa}$. Entre esta tensão e a referente à capacidade de campo $(0,008 \mathrm{MPa})$, a quantidade de água retida no solo, até a profundidade de $0,50 \mathrm{~m}$, era igual a $25 \mathrm{~mm}$. Após cada irrigação, a quantidade de água aplicada foi medida por meio de quatro coletores instalados em cada faixa $\mathrm{A}$

Além da produtividade e seus componentes, foram avaliados, por ocasião da floração (50 dias após a emergência), o índice de área foliar, a produção de matéria seca da parte aérea e o teor de $\mathrm{N}$ nas folhas. Estas três últimas variáveis foram avaliadas apenas nas faixas que receberam as lâminas 2 ou 5 de água. No primeiro e no último ano foram avaliados também, na floração, a resistência do solo à penetração e a densidade radicular, nas faixas que receberam a lâmina 2 de água. 
A resistência do solo à penetração foi determinada, com duas repetições por subparcela, mediante o uso de um penetrômetro de impacto Modelo IAA/PLANALSUCARStolf. Os dados obtidos com o penetrômetro foram transformados em resistência do solo pelo uso da fórmula proposta por Stolf (1991), adaptada para expressão dos resultados em $\mathrm{kPa}$ :

$\mathrm{R}=549,2+675,7 \mathrm{~N}$

onde:

$\mathrm{R}=$ resistência do solo, em $\mathrm{kPa}$;

$\mathrm{N}=$ número de impactos $\mathrm{dm}^{-1}$.

Para determinação da massa de raízes por volume de solo $\left(\mathrm{g} \mathrm{dm}^{-3}\right)$, coletaram-se, com trado de $0,5 \mathrm{dm}^{3}$, amostras de raízes mais solo, a $5 \mathrm{~cm}$ da linha das plantas, até $50 \mathrm{~cm}$ de profundidade, em intervalos de $10 \mathrm{~cm}$, em duas repetições por subparcela. As raízes foram separadas do solo por lavagem e peneiramento. As raízes foram secadas em estufa a $75^{\circ} \mathrm{C}$, e pesadas. Para avaliar a distribuição relativa do sistema radicular, os valores obtidos em cada profundidade do solo foram transformados em porcentagem do total.

Para determinação da área foliar colheram-se três plantas por subparcela. Determinou-se a área foliar com medidor de área marca LI-COR, modelo LI 3000. Após a secagem das plantas em estufa a $75^{\circ} \mathrm{C}$, determinou-se a massa da parte aérea. $\mathrm{O}$ índice de área foliar foi obtido pela multiplicação da área foliar média de uma planta, $\mathrm{em}^{2}$, pelo número de plantas por $\mathrm{m}^{2}$. A produção de matéria seca da parte aérea foi obtida pela multiplicação da massa média de uma planta, em g, pelo número de plantas por $\mathrm{m}^{2}$. O teor de $\mathrm{N}$ foi determinado em $200 \mathrm{mg}$ de amostra digerida com $3 \mathrm{~mL}$ de $\mathrm{H}_{2} \mathrm{SO}_{4}$ em presença de $1,1 \mathrm{~g}$ de uma mistura de selênio em pó, sulfato de cobre e sulfato de potássio, pelo método de Kjeldahl

Os dados obtidos foram submetidos à análise de variância e de regressão. A dose máxima econômica foi calculada igualando-se a derivada primeira da função de produção, determinada por meio da equação de regressão, à relação de preços do $\mathrm{N}$ e do feijão. Foram considerados os preços vigentes na praça de Goiânia, em outubro/98, com relação ao $\mathrm{N}$, na forma de sulfato de amônio, e ao feijão, $\mathrm{R} \$ 1,40 / \mathrm{kg}$ e $\mathrm{R} \$ 1,00 / \mathrm{kg}$, respectivamente

\section{Resultados e Discussão}

A resistência do solo à penetração $(\mathrm{R})$, em 1995 (Figura 1), até cerca de $24 \mathrm{~cm}$ de profundidade, foi semelhante nas faixas com os tratamentos arado de aiveca e grade e, por sua vez, menor que na faixa com o tratamento plantio direto. Até esta profundidade houve pouca variação no valor de $\mathrm{R}$, em cada preparo do solo, refletindo as condições de preparos do solo anteriores à instalação do experimento.

A grade apresentou, em 1998, grande aumento no valor de R em camadas mais profundas que $12 \mathrm{~cm}$, atingindo valores máximos ao redor de $28 \mathrm{~cm}$.

As diferenças entre o arado e a grade, com relação aos valores de $\mathrm{R}$, estão relacionadas à profundidade e modo de ação de cada implemento. A grade trabalhou entre 10 e $15 \mathrm{~cm}$ de profundidade, assim, após esta profundidade, o solo não foi revolvido e sofreu a pressão do implemento, formando o chamado pé-de-grade. Por outro lado, o arado revolveu o solo mais profundamente, entre 30 e $35 \mathrm{~cm}$. Smittle \& Threadgill (1977) verificaram aumentos no valor de R após 10 e $28 \mathrm{~cm}$, em solos preparados com grade aradora e arado de aiveca, respectivamente.

O plantio direto apresentou, em 1998, até cerca de $12 \mathrm{~cm}$ de profundidade, maiores valores de $\mathrm{R}$ que $\mathrm{o}$ arado ou a grade. Após esta profundidade, até cerca de $40 \mathrm{~cm}$, os valores de $\mathrm{R}$ foram semelhantes aos da grade, e maiores que os observados no preparo com arado. Valores elevados de R na camada superficial, no plantio direto, também foram verificados por Stone \& Silveira (1999). O arranjamento natural do solo pelo seu não-revolvimento e a movimentação de máquinas e implementos agrícolas ocasionam aumento da densidade do solo e redução da porosidade total, na camada superficial, nos primeiros anos de implantação do plantio direto (Vieira \& Muzilli, 1984).

No primeiro ano, apesar da semelhança nos valores de R entre os sistemas de preparo do solo, decorrente da condição inicial da área experimental, o preparo com arado apresentou tendência de maior massa de raízes por volume de solo ao longo do perfil (Tabela 1). No quarto ano, apesar das diferenças entre os sistemas de preparo do solo quanto aos valores de R, a tendência foi a mesma. Considerando os dois anos, observa-se que $76 \%$ a $90 \%$ das raízes concentraram-se nos primeiros $30 \mathrm{~cm}$ de profundidade do solo. Estes valores estão de acordo com os observados por Pires et al. (1991), Stone \& Pereira (1994) e Stone \& Silveira (1999). No preparo com arado, a distribuição do sistema radicular em profundidade foi mais uniforme. No quarto ano, apesar dos maiores valores de $\mathrm{R}$ observados no plantio direto, a distribuição do sistema radicular foi mais uniforme que no preparo com grade. 
Resistência à penetração $(\mathrm{kPa})$
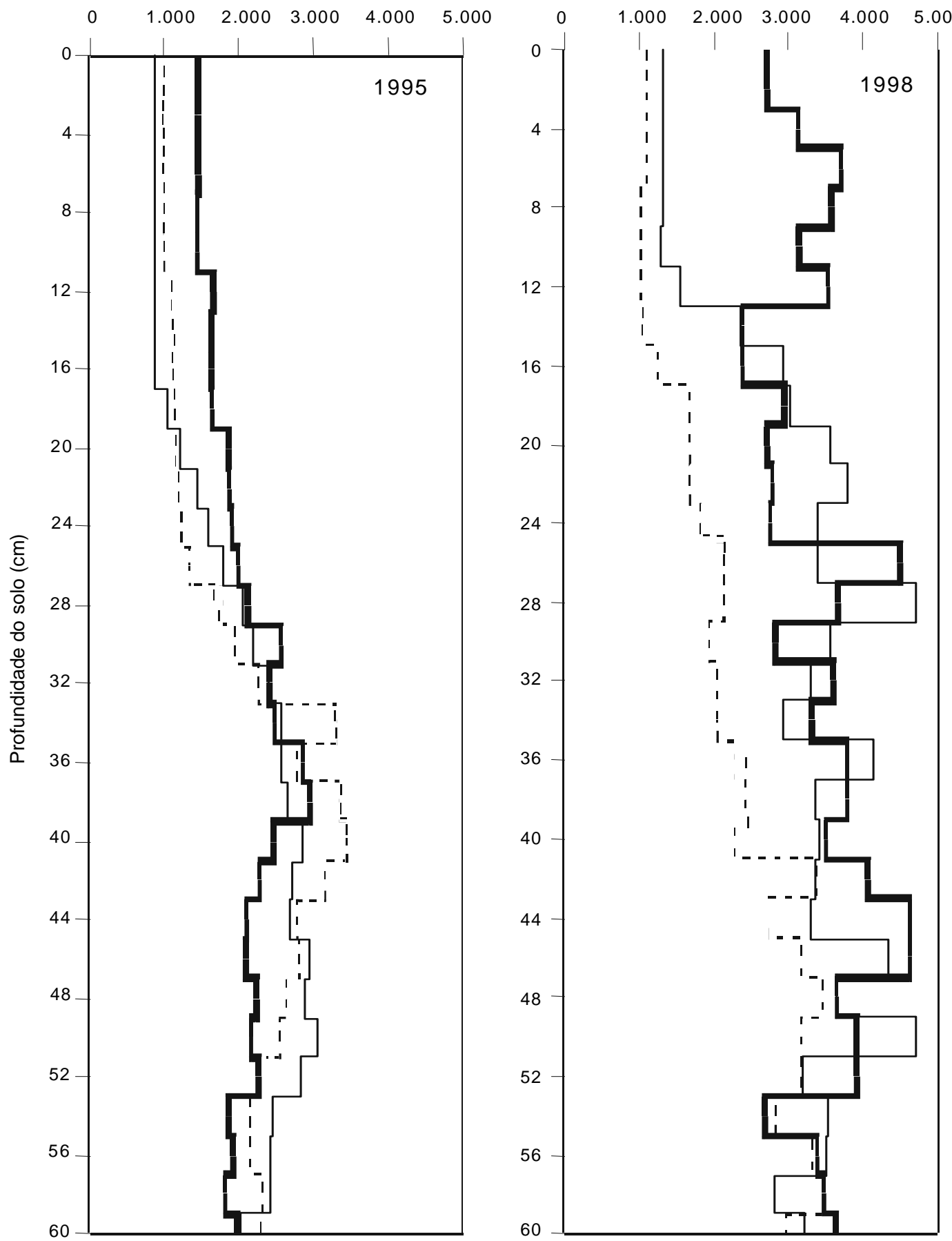

Figura 1. Resistência do solo à penetração, no perfil de 0-60 cm, em três sistemas de preparo do solo: arado (---), grade (-) e plantio direto (—), por ocasião da floração do feijoeiro. 
Tabela 1. Massa de raízes do feijoeiro por volume de solo, em diferentes profundidades, em três sistemas de preparo do solo, em 1995 e 1998.

\begin{tabular}{|c|c|c|c|c|c|c|c|c|c|c|c|c|}
\hline \multirow{3}{*}{$\begin{array}{l}\text { Camada do } \\
\text { solo }(\mathrm{cm})\end{array}$} & \multicolumn{4}{|c|}{ Grade } & \multicolumn{4}{|c|}{ Arado } & \multicolumn{4}{|c|}{ Plantio direto } \\
\hline & \multicolumn{2}{|c|}{1995} & \multicolumn{2}{|c|}{1998} & \multicolumn{2}{|c|}{1995} & \multicolumn{2}{|c|}{1998} & \multicolumn{2}{|c|}{1995} & \multicolumn{2}{|c|}{1998} \\
\hline & $\left(\mathrm{g} \mathrm{dm}^{-3}\right)$ & $(\%)$ & $\left(\mathrm{g} \mathrm{dm}^{-3}\right)$ & $\overline{(\%)}$ & $\left(\mathrm{g} \mathrm{dm}^{-3}\right)$ & $(\%)$ & $\left(\mathrm{g} \mathrm{dm}^{-3}\right)$ & $(\%)$ & $\left(\mathrm{g} \mathrm{dm}^{-3}\right)$ & $(\%)$ & $\left(\mathrm{g} \mathrm{dm}^{-3}\right)$ & (\%) \\
\hline $0-10$ & 1,20 & 47,6 & 0,89 & 44,5 & 1,24 & 39,1 & 0,80 & 31,2 & 1,32 & 51,8 & 0,61 & 30,2 \\
\hline $10-20$ & 0,74 & 29,4 & 0,43 & 21,5 & 0,82 & 25,9 & 0,90 & 35,2 & 0,61 & 23,9 & 0,63 & 31,2 \\
\hline $20-30$ & 0,33 & 13,1 & 0,20 & 10,0 & 0,69 & 21,8 & 0,50 & 19,5 & 0,32 & 12,5 & 0,35 & 17,3 \\
\hline $30-40$ & 0,16 & 6,3 & 0,22 & 11,0 & 0,19 & 6,0 & 0,20 & 7,8 & 0,16 & 6,3 & 0,22 & 10,9 \\
\hline $40-50$ & 0,09 & 3,6 & 0,26 & 13,0 & 0,23 & 7,2 & 0,16 & 6,3 & 0,14 & 5,5 & 0,21 & 10,4 \\
\hline Total & 2,52 & 100,0 & 2,00 & 100,0 & 3,17 & 100,0 & 2,56 & 100,0 & 2,55 & 100,0 & 2,02 & 100,0 \\
\hline
\end{tabular}

A análise conjunta dos experimentos instalados em 1995 e 1996 mostrou que não houve efeito significativo de ano nem das interações entre ano e tratamentos sobre as variáveis analisadas. Desta maneira, foi considerada a média dos dois anos.

Os sistemas de preparo do solo afetaram significativamente a produtividade e alguns de seus componentes, mas não interagiram significativamente com os demais tratamentos. O plantio direto apresentou menor número de vagens por planta e massa de 100 grãos, em comparação com os demais sistemas de preparo do solo (Tabela 2). Isto se refletiu na sua menor produtividade, a qual pode estar associada ao menor teor de $\mathrm{N}$ nas plantas, que provocou redução no índice de área foliar e tendência de redução na produção de matéria seca (Tabela 3). Segundo os critérios apresentados em Rosolem \& Marubayashi (1994), o teor de N verificado nas plantas do tratamento plantio direto é considerado médio e o das plantas dos demais sistemas de preparo do solo é adequado. Em gramíneas (Muzilli, 1983) e no feijoeiro (Silva, 1998) foi constatado maior necessidade de $\mathrm{N}$ no plantio direto, em comparação a outros preparos que mobilizam o solo. De acordo com Kurihara et al. (1998), isto deve-se à imobilização microbiana do $\mathrm{N}$ do fertilizante. No feijoeiro, quando o $\mathrm{N}$ está deficiente, poucas flores se desenvolvem, resultando em número reduzido de vagens, e as sementes são pequenas, tendo, em conseqüência, baixa massa (Oliveira et al., 1996). Vários pesquisadores (Mullins \& Straw, 1988; Sampaio et al., 1989; Siqueira, 1989) também observaram maior produtividade do feijoeiro em preparo convencional, quando comparado com o plantio direto.

Não houve interação significativa entre doses de $\mathrm{N}$ e lâminas de água, com relação aos componentes
Tabela 2. Produtividade do feijoeiro e seus componentes, em três sistemas de preparo do solo ${ }^{(1)}$.

\begin{tabular}{|c|c|c|c|}
\hline \multirow[t]{2}{*}{ Ano } & \multicolumn{3}{|c|}{ Sistema de preparo do solo } \\
\hline & Grade & Arado & Plantio direto \\
\hline & \multicolumn{3}{|c|}{ Estande final (plantas $\mathrm{m}^{-2}$ ) } \\
\hline 1995 e 1996 & $25,9 a$ & $25,0 \mathrm{a}$ & $24,9 a$ \\
\hline 1997 & $18,8 \mathrm{aA}$ & $21,7 \mathrm{aA}$ & $20,6 \mathrm{aB}$ \\
\hline \multirow[t]{2}{*}{1998} & $23,5 \mathrm{bA}$ & $28,1 \mathrm{abA}$ & $31,4 \mathrm{aA}$ \\
\hline & \multicolumn{3}{|c|}{ Vagens por planta $\left(\mathrm{n}^{\mathrm{o}}\right)$} \\
\hline 1995 e 1996 & $8,8 \mathrm{a}$ & $9,2 \mathrm{a}$ & $6,0 \mathrm{~b}$ \\
\hline 1997 & $12,6 \mathrm{aA}$ & $13,2 \mathrm{aA}$ & $10,8 \mathrm{aA}$ \\
\hline \multirow[t]{2}{*}{1998} & $9,3 \mathrm{aA}$ & $10,6 \mathrm{aA}$ & $11,0 \mathrm{aA}$ \\
\hline & \multicolumn{3}{|c|}{ Grãos por vagem $\left(\mathrm{n}^{\mathrm{o}}\right)$} \\
\hline 1995 e 1996 & $4,8 \mathrm{a}$ & $4,9 \mathrm{a}$ & $4,5 \mathrm{a}$ \\
\hline 1997 & $4,5 \mathrm{abA}$ & $4,6 \mathrm{aA}$ & $4,0 \mathrm{bB}$ \\
\hline \multirow[t]{2}{*}{1998} & $5,0 \mathrm{aA}$ & $4,8 \mathrm{aA}$ & $4,8 \mathrm{aA}$ \\
\hline & \multicolumn{3}{|c|}{ Massa de 100 grãos (g) } \\
\hline 1995 e 1996 & $24,20 \mathrm{a}$ & $23,78 \mathrm{a}$ & $21,71 b$ \\
\hline 1997 & $27,61 \mathrm{aA}$ & $28,35 \mathrm{aA}$ & $24,12 \mathrm{aA}$ \\
\hline \multirow[t]{2}{*}{1998} & $25,82 \mathrm{aA}$ & $26,72 \mathrm{aA}$ & $26,28 \mathrm{aA}$ \\
\hline & \multicolumn{3}{|c|}{ Produtividade $\left(\mathrm{kg} \mathrm{ha}^{-1}\right)$} \\
\hline 1995 e 1996 & $1.571 \mathrm{a}$ & $1.770 \mathrm{a}$ & $1.072 b$ \\
\hline 1997 & $2.058 \mathrm{aA}$ & $2.716 \mathrm{aA}$ & $1.652 \mathrm{aB}$ \\
\hline 1998 & $1.784 \mathrm{aA}$ & $2.110 \mathrm{aA}$ & $2.542 \mathrm{aA}$ \\
\hline
\end{tabular}

(1)Em cada linha, valores seguidos pela mesma letra minúscula não diferem significativamente entre si a 5\% de probabilidade, pelo teste de Tukey; em cada coluna, a letra maiúscula compara o ano de 1997 com o de 1998.

da produtividade. Entre estes, apenas o número de vagens por planta e a massa de 100 grãos responderam significativamente ao aumento nas doses de N, resultante da grande influência do $\mathrm{N}$ nestes componentes, como discutido anteriormente. $\mathrm{O}$ número de vagens por planta (VP) respondeu linearmente: $\mathrm{VP}=6,6+0,05 \mathrm{~N}, \mathrm{R}^{2}=0,992^{* *}$. A resposta da massa de 100 grãos (M100) foi quadrática: $\mathrm{M} 100=22,6-0,02 \mathrm{~N}+0,0009 \mathrm{~N}^{2}, \mathrm{R}^{2}=0,991^{*}$.

As quantidades médias de água aplicadas durante todo o ciclo do feijoeiro, em 1995 e 1996, corres- 
Tabela 3. Índice de área foliar, produção de matéria seca, teor e quantidade de nitrogênio absorvido pelo feijoeiro, em três sistemas de preparo do solo, por ocasião da floração( ${ }^{(1)}$

\begin{tabular}{|c|c|c|c|}
\hline \multirow[t]{2}{*}{ Ano } & \multicolumn{3}{|c|}{ Sistema de preparo do solo } \\
\hline & Grade & Arado & Plantio direto \\
\hline & \multicolumn{3}{|c|}{ Índice de área foliar $\left(\mathrm{m}^{2} \mathrm{~m}^{-2}\right)$} \\
\hline 1995 e 1996 & $2,8 \mathrm{a}$ & $2,5 \mathrm{~b}$ & $2,4 \mathrm{c}$ \\
\hline \multirow[t]{2}{*}{1997 e 1998} & $2,6 \mathrm{~b}$ & $3,7 \mathrm{a}$ & $2,9 \mathrm{~b}$ \\
\hline & \multicolumn{3}{|c|}{ Matéria seca $\left(\mathrm{g} \mathrm{m}^{-2}\right)$} \\
\hline 1995 e 1996 & $206,2 \mathrm{a}$ & $206,3 \mathrm{a}$ & $151,4 \mathrm{a}$ \\
\hline \multirow[t]{2}{*}{1997 e 1998} & $184,7 \mathrm{~b}$ & $272,0 \mathrm{a}$ & $187,6 \mathrm{~b}$ \\
\hline & \multicolumn{3}{|c|}{ Teor de N (\%) } \\
\hline 1995 e 1996 & $3,0 \mathrm{ab}$ & $3,1 \mathrm{a}$ & $2,7 \mathrm{~b}$ \\
\hline \multirow[t]{2}{*}{1997 e 1998} & $3,3 \mathrm{a}$ & $3,1 \mathrm{a}$ & $3,0 \mathrm{a}$ \\
\hline & \multicolumn{3}{|c|}{$\mathrm{N}$ absorvido $\left(\mathrm{kg} \mathrm{ha}^{-1}\right)$} \\
\hline 1995 e 1996 & $64,2 \mathrm{a}$ & $57,0 \mathrm{a}$ & $47,7 \mathrm{a}$ \\
\hline 1997 e 1998 & $58,4 \mathrm{~b}$ & $79,3 \mathrm{a}$ & $54,7 \mathrm{~b}$ \\
\hline
\end{tabular}

${ }^{(1)}$ Em cada linha, valores seguidos pela mesma letra não diferem significativamente entre si a $5 \%$ de probabilidade, pelo teste de Tukey.

pondentes às lâminas $1,2,3,4$ e 5 , foram iguais a $326,4,310,2,304,6,283,8$ e $259,8 \mathrm{~mm}$, respectivamente. A resposta do número de vagens por planta $(\mathrm{VP})$ e o número de grãos por vagem $(\mathrm{GV})$, às lâminas de água foi quadrática $(\mathrm{VP}=-25,3+0,19 \mathrm{~L}$ $0003 \mathrm{~L}^{2}, \mathrm{R}^{2}=0,985^{*} ; \mathrm{GV}=-10,6+0,08 \mathrm{~L}-0,0001 \mathrm{~L}^{2}$, $\mathrm{R}^{2}=0,984^{*}$ ), indicando que mesmo um estresse hídrico de pequena intensidade na fase vegetativa já tem reflexo negativo sobre eles. Miranda \& Belmar (1977), Hostalácio \& Válio (1984) e Weaver et al. (1984) também observaram redução nesses componentes em condições de deficiência hídrica

Houve interação significativa entre doses de $\mathrm{N} \mathrm{e}$ lâminas de água com relação à produtividade do feijoeiro (Tabela 4). Nas lâminas 1 (326,4 mm), $2(310,2)$ e $5(259,8 \mathrm{~mm})$ de água, a resposta ao $\mathrm{N}$ aplicado em cobertura foi linear e significativa. No tratamento que recebeu a lâmina $3(304,6 \mathrm{~mm})$ a resposta foi quadrática e significativa, sendo o máximo atingido com $50 \mathrm{~kg} \mathrm{ha}^{-1}$ de N. Este nível de irrigação limitou a resposta do feijoeiro ao $\mathrm{N}$, quando comparado às lâminas 1 e 2 . No caso da lâmina 5 (259,8 mm), o $\mathrm{N}$ compensou em parte o efeito da deficiência hídrica, como observado por Costa (1986) e Frizzone et al. (1987). O aumento da produtividade do feijoeiro com o incremento da dose de $\mathrm{N}$ aplicada em cobertura também pode ser explicado pelo efeito significativo, linear e positivo do $\mathrm{N}$ sobre o
Tabela 4. Equações ajustadas da produtividade $\left(\mathrm{kg} \mathrm{ha}^{-1}\right)$ em resposta às doses de nitrogênio $(\mathrm{N})$ aplicadas em cobertura e da lâmina total (L) de água aplicada, em 1995 e 1996.

\begin{tabular}{rlr}
\hline Tratamento & Equação & $\mathrm{R}^{2}$ \\
\hline \multicolumn{3}{c}{ Doses de N $\left(\mathrm{kg} \mathrm{ha}^{-1}\right)$} \\
0 & PROD $=-30196,8+206,91 \mathrm{~L}-0,339 \mathrm{~L}^{2}$ & $0,965^{*}$ \\
20 & PROD $=-3475,2+16,48 \mathrm{~L}$ & $0,817^{*}$ \\
40 & PROD $=-13769,9+85,35 \mathrm{~L}-0,112 \mathrm{~L}^{2}$ & $0,996^{* *}$ \\
60 & PROD $=-15015,4+94,95 \mathrm{~L}-0,130 \mathrm{~L}^{2}$ & $0,991^{* *}$ \\
\hline \multicolumn{3}{c}{ Lâminas de água $(\mathrm{mm})$} \\
326,4 & PROD $=1304,7+16,42 \mathrm{~N}$ & $0,908^{*}$ \\
310,2 & PROD $=1441,2+11,45 \mathrm{~N}$ & $0,903^{*}$ \\
304,6 & PROD $=1385,2+17,26 \mathrm{~N}-0,174 \mathrm{~N}^{2}$ & $0,999^{* *}$ \\
283,8 & Não houve ajuste significativo & \\
259,8 & PROD $=661,0+4,06 \mathrm{~N}$ & $0,962^{*}$ \\
\hline
\end{tabular}

índice de área foliar (IAF), produção de matéria seca (MS), teor de $\mathrm{N}$ nas plantas (TN) e quantidade de $\mathrm{N}$ absorvido (QN) (Tabela 5).

A resposta da produtividade à lâmina total de água aplicada foi significativa em todos os tratamentos de $\mathrm{N}$, decrescendo à medida que a irrigação foi realizada com menores lâminas (Tabela 4). Isto confirma o observado por Maurer et al. (1969) e Miranda \& Belmar (1977) de que o déficit hídrico na fase vegetativa também é prejudicial para o feijoeiro, pois, os valores de IAF, MS, TN e QN observados com a lâmina 5 de água $(259,8 \mathrm{~mm}), 1,4 \mathrm{~m}^{2} \mathrm{~m}^{-2}$, $135,5 \mathrm{~g} \mathrm{~m}^{-2}, 2,8 \%$ e $37,6 \mathrm{~kg} \mathrm{ha}^{-1}$, respectivamente, foram significativamente menores em relação aos observados com a lâmina 2 de água $(310,2 \mathrm{~mm})$, $3,0 \mathrm{~m}^{2} \mathrm{~m}^{-2}, 240,4 \mathrm{~g} \mathrm{~m}^{-2}, 3,1 \%$ e $75,0 \mathrm{~kg} \mathrm{ha}^{-1}$, respectivamente.

A análise conjunta dos experimentos instalados em 1997 e 1998 mostrou que houve interação significativa entre ano e preparo do solo, apenas com relação às variáveis estande final, número de grãos por vagem e produtividade. Em 1997 não houve efeito significativo dos sistemas de preparo do solo sobre o estande final e, em 1998, o plantio direto propiciou maior estande final que a grade (Tabela 2). Em 1998 não houve diferença significativa entre os sistemas de preparo do solo quanto ao número de grãos por vagem, enquanto em 1997 o menor valor desta variável ocorreu no plantio direto. Com relação a estas duas variáveis, os valores obtidos no plantio direto em 1998 foram significativamente superiores aos obtidos em 1997, não havendo diferenças significati- 
Tabela 5. Equações ajustadas do índice de área foliar (IAF), da produção de matéria seca (MS), do teor (TN) e da quantidade $(\mathrm{QN})$ de nitrogênio absorvido em resposta às doses de nitrogênio $(\mathrm{N})$ aplicadas em cobertura.

\begin{tabular}{lcc}
\hline Ano & Equação & $\mathrm{R}^{2}$ \\
\hline & \multicolumn{1}{c}{ Índice de área foliar $\left(\mathrm{m}^{2} \mathrm{~m}^{-2}\right)$} \\
1995 e 1996 & $\mathrm{IAF}=2,3+0,01 \mathrm{~N}$ & $0,912^{*}$ \\
1997 e 1998 & $\mathrm{IAF}=2,3+0,01 \mathrm{~N}$ & $0,980^{* *}$ \\
\hline \multicolumn{3}{c}{ Matéria seca $\left(\mathrm{g} \mathrm{m}^{-2}\right)$} \\
1995 e 1996 & $\mathrm{MS}=160,9+0,99 \mathrm{~N}$ & $0,982^{* *}$ \\
1997 e 1998 & $\mathrm{MS}=165,4+0,79 \mathrm{~N}$ & $0,951^{*}$ \\
\hline \multicolumn{3}{c}{ Teor de $\mathrm{N}(\%)$} \\
1995 e 1996 & $\mathrm{TN}=2,8+0,005 \mathrm{~N}$ & $0,999^{* *}$ \\
1997 e 1998 & $\mathrm{TN}=2,8+0,006 \mathrm{~N}$ & $0,982^{* *}$ \\
\hline \multicolumn{3}{c}{$\mathrm{N}$ absorvido $\left(\mathrm{kg} \mathrm{ha}^{-1}\right)$} \\
1995 e 1996 & $\mathrm{QN}=45,8+0,35 \mathrm{~N}$ & $0,994^{* *}$ \\
1997 e 1998 & $\mathrm{QN}=42,0+0,62 \mathrm{~N}-0,003 \mathrm{~N}^{2}$ & $0,998^{*}$ \\
\hline
\end{tabular}

vas entre anos para os outros preparos do solo. Tais resultados contribuíram para que, apesar de não haver diferença significativa entre os preparos do solo, nos dois anos, quanto à produtividade, houvesse aumento relativo de mais de $50 \%$ na produtividade observada sob plantio direto em 1998 em relação a 1997. Nos outros sistemas de preparo do solo houve redução da produtividade, embora não-significativa. Com o aumento nas doses de $\mathrm{N}$ nesses dois anos, em relação aos dois primeiros anos, o teor de $\mathrm{N}$ nas plantas sob plantio direto (Tabela 3 ) estava adequado conforme Rosolem \& Marubayashi (1994).

O IAF, a MS e a QN foram maiores no preparo com arado, explicando, em parte, a maior média de produtividade verificada neste sistema de preparo do solo. Além do maior teor de $\mathrm{N}$ nas plantas, a melhor estruturação do solo, como ocorre em plantio direto com o passar do tempo (Urchei, 1996; Silva, 1998), resultando em melhor distribuição do sistema radicular em profundidade (Tabela 1), deve ter contribuído para que a produtividade sob plantio direto aumentasse com o tempo de cultivo. Por outro lado, o aumento na compactação do solo deve ter contribuído para reduzir a produtividade sob grade. Mullins et al. (1980) e Zaffaroni et al. (1991) não encontraram diferenças na produtividade do feijoeiro em plantio direto ou preparo convencional do solo, enquanto Urchei (1996) e Stone \& Silveira (1999), sob irrigação, verificaram maior produtividade em plantio direto.
As quantidades médias de água aplicadas durante todo o ciclo do feijoeiro, em 1997 e 1998, correspondentes às lâminas $1,2,3,4$ e 5, foram iguais a $366,1,335,1,315,7,293,7$ e $260,7 \mathrm{~mm}$, respectivamente. Houve interação significativa entre lâmina de água e preparo do solo, com relação às variáveis massas de 100 grãos (M100) e à produtividade (PROD), as quais decresceram linearmente com o decréscimo da lâmina de água aplicada (M100 = $13,2+0,04 \mathrm{~L}, \mathrm{R}^{2}=0,943^{* *} ; \mathrm{PROD}=-29,8+6,20 \mathrm{~L}$, $\left.\mathrm{R}^{2}=0,931^{* *}\right)$. Nos demais preparos não houve efeito significativo da lâmina de água. A demanda evaporativa da atmosfera, expressa pela evapotranspiração de referência, durante o período de aplicação das lâminas de água, foi menor em 1997 e 1998 (138,6 mm e 140,9 mm, respectivamente), em relação a 1995 e 1996 (165,5 mm e 155,7 mm, respectivamente), devido, basicamente, à antecipação da data de semeadura. Esta menor demanda contribuiu para que nos tratamentos em que o sistema radicular estivesse melhor distribuído (arado e plantio direto), a redução da lâmina de água na fase vegetativa do feijoeiro não provocasse estresse hídrico nos dois últimos anos. Não houve diferença significativa entre os valores de IAF, MS, TN e QN observados com a lâmina 5 de água $(260,7 \mathrm{~mm}), 2,8 \mathrm{~m}^{2} \mathrm{~m}^{-2}$, $211,3 \mathrm{~g} \mathrm{~m}^{-2}, 3,0 \%$ e $61,6 \mathrm{~kg} \mathrm{ha}^{-1}$, respectivamente, em relação aos observados com a lâmina $2(335,1 \mathrm{~mm})$, $3,3 \mathrm{~m}^{2} \mathrm{~m}^{-2}, 217,6 \mathrm{~g} \mathrm{~m}^{-2}, 3,2 \%$ e $67,3 \mathrm{~kg} \mathrm{ha}^{-1}$, respectivamente.

Não houve interação significativa entre doses de $\mathrm{N}$ e quaisquer outros tratamentos. Como nos dois primeiros anos, apenas o número de grãos por vagem, a massa de 100 grãos e a produtividade responderam significativamente ao aumento nas doses de N. O número de vagens por planta (VP) e a massa de 100 grãos responderam linearmente: $\mathrm{VP}=9,2+$ $0,03 \mathrm{~N}, \mathrm{R}^{2}=0,904^{*}$ e $\mathrm{M} 100=25,1+0,02 \mathrm{~N}$, $\mathrm{R}^{2}=0,986^{* *}$, enquanto a produtividade apresentou resposta quadrática (Figura 2). A maior dose de $\mathrm{N}$ aplicada em cobertura (120 kg ha-1) não foi suficiente para alcançar a produtividade máxima do feijoeiro (Figura 2). Pela equação ajustada, o rendimento máximo seria obtido com $137 \mathrm{~kg} \mathrm{ha}^{-1}$ de N. Considerando os preços praticados em Goiânia, em outubro de 1998, representados pela relação 1,4:1 (preço de um kg de N:preço de um kg de feijão), a dose máxi- 


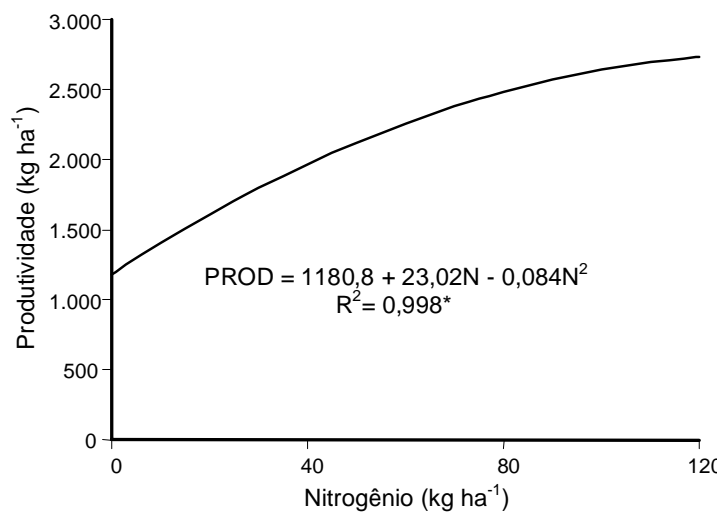

Figura 2. Produtividade do feijoeiro, cultivar Aporé, em resposta às doses de nitrogênio aplicadas em cobertura (médias de 1997 e 1998).

ma econômica foi igual a $129 \mathrm{~kg} \mathrm{ha}^{-1}$ de $\mathrm{N}$, extrapolando a dose máxima estudada. Considerando redução de $50 \%$ no preço do feijão, a dose econômica ainda seria elevada, cerca de $121 \mathrm{~kg} \mathrm{ha}^{-1}$ de N. Essas doses estão na faixa dos valores ótimos econômicos, de $114 \mathrm{~kg} \mathrm{ha}^{-1}$ de N (Frizzone et al., 1987) e de $137 \mathrm{~kg} \mathrm{ha}^{-1}$ de N (Barbosa Filho \& Silva, 1994), e acima da faixa de 80 a $100 \mathrm{~kg} \mathrm{ha}^{-1}$ de N (Silva, 1998), dependendo do sistema agrícola.

Como nos dois primeiros anos, o incremento na dose de $\mathrm{N}$ aplicada em cobertura também aumentou o índice de área foliar, produção de matéria seca $\mathrm{e}$ teor de $\mathrm{N}$ (Tabela 5). A quantidade de $\mathrm{N}$ absorvido apresentou resposta quadrática, com o máximo sendo alcançado com $103 \mathrm{~kg} \mathrm{ha}^{-1}$ de N.

\section{Conclusões}

1. O estresse hídrico na fase vegetativa reduz a produtividade do feijoeiro.

2. O aumento na dose de nitrogênio em cobertura compensa, em parte, o efeito negativo do estresse hídrico na fase vegetativa do feijoeiro.

3. A produtividade do feijoeiro sob plantio direto aumenta com o tempo.

4. Os sistemas de preparo do solo não afetam a resposta do feijoeiro ao nitrogênio.

\section{Referências}

BARBOSA FILHO, M. P.; SILVA, O. F. da. Aspectos agroeconômicos da calagem e da adubação nas culturas de arroz e feijão irrigados por aspersão. Pesquisa Agropecuária Brasileira, Brasília, v. 29, n. 11, p. 1657 1667, nov. 1994

COSTA, R. C. L. Efeito de níveis de água e de doses de nitrogênio sobre o crescimento, morfologia, partição de assimilados e troca de $\mathrm{CO}$ em Phaseolus vulgaris $\mathrm{L}$. Viçosa : UFV, 1986. 90 p. Dissertação de Mestrado.

FRIZZONE, J. A.; OLITTA, A. F. L.; PEREIRA, G. T. Funções de resposta do feijoeiro (Phaseolus vulgaris L.) ao uso de nitrogênio e lâmina de irrigação. II. Maximização da receita líquida. ITEM, Brasília, n. 30, p. 27-31, 1987.

HOSTALÁCIO, S.; VÁLIO, I. F. M. Desenvolvimento de plantas de feijão cv. Goiano Precoce, em diferentes regimes de irrigação. Pesquisa Agropecuária Brasileira, Brasília, v. 19, n. 2, p. 211-218, fev. 1984.

KURIHARA, C. H.; FABRÍCIO, A. C.; PITOL, C.; STAUT, L. A.; KICHEL, A. N.; MACEDO, M. C. M.; ZIMMER, A. H.; WIETHOLTER, S. Adubação. In SALTON, J. C.; HERNANI, L. C.; FONTES, C. Z. (Org.). Sistema plantio direto: o produtor pergunta, a Embrapa responde. Brasília : Embrapa-SPI, 1998. p. 135-144.

MAURER, A. P.; ORMROD, D. P.; SCOTT, N. J. Effect of five soil water regimes on growth and composition of snap beans. Canadian Journal of Plant Science, Ottawa, v. 49, n. 3 , p. $271-278,1969$

MIRANDA, N. O.; BELMAR, N. C. Déficit hídrico y frecuencia de riego en frijol (Phaseolus vulgaris L.). Agricultura Técnica, Santiago, v. 37, n. 3, p. 111-117, 1977.

MULLINS, C. A.; STRAW, R. A. Production of snap beans as affected by soil tillage method and row spacing. Journal of the American Society for Horticultural Science, Alexandria, v. 113, n. 5, p. 667-669, 1988.

MULLINS, C. A.; TOMPKINS, F. D.; PARKS, W. L. Effects of tillage methods on soil nutrient distribution, plant nutrient absorption, stand, and yield of snap beans and lima beans. Journal of the American Society for Horticultural Science, Alexandria, v. 105, p. 591-593, 1980.

MUZILLI, O. Influência do sistema de plantio direto, comparado ao convencional, sobre a fertilidade da camada arável do solo. Revista Brasileira de Ciência do Solo, Campinas, v. 7, n. 1, p. 95-102, 1983.

OLIVEIRA, I. P. de; ARAUJO, R. S.; DUTRA, L. G. Nutrição mineral e fixação biológica de nitrogênio. In: ARAUJO, R. S.; RAVA, C. A.; STONE, L. F.; 
ZIMMERMANN, M. J. de O. (Coord.). Cultura do feijoeiro comum no Brasil. Piracicaba : POTAFOS, 1996. p. $169-221$.

PIRES, R. C. de; ARRUDA, F. B.; FUJIWARA, M.; SAKAI, E.; BORTOLETTO, N. Profundidade do sistema radicular das culturas de feijão e trigo sob pivô central. Bragantia, Campinas, v. 50, n. 1, p. 153-162, 1991.

ROSOLEM, C. A.; MARUBAYASHI, O. M. Seja o doutor do seu feijoeiro. Informações Agronômicas, Piracicaba, n. 68, p. 1-16, 1994.

SAMPAIO, G. V.; GALVÃO, J. D.; FONTES, L. A. N.; FIGUEIREDO, M. de S.; CARDOSO, A. A. Efeitos de sistemas de preparo do solo sobre o consórcio milho-feijão (Phaseolus vulgaris L.). Revista Ceres, Viçosa, v. 36 , p. $465-482,1989$

SILVA, C. C. da. Influência de sistemas agrícolas na resposta do feijoeiro (Phaseolus vulgaris L.) irrigado à adubação nitrogenada. Goiânia : UFG, 1998. 180 p. Tese de Doutorado

SILVEIRA, P. M. da; STONE, L. F.; RIOS, G. P.; COBUCCI, T.; AMARAL, A. M. do. A irrigação e a cultura do feijoeiro. Goiânia : Embrapa-CNPAF, 1996. 51 p. (Embrapa-CNPAF. Documentos, 63).

SIQUEIRA, N. de S. Efeitos de sistemas de preparo do solo sobre a cultura do feijoeiro (Phaseolus vulgaris $\mathrm{L}$.) e sobre algumas propriedades físicas e químicas do solo. Viçosa : UFV, 1989. 106 p. Dissertação de Mestrado

SMITTLE, D. A.; THREADGILL, E. D. Response of southern pea (Vigna unguiculata L.) to tillage methods. HortScience, Alexandria, v. 12, p. 556-558, 1977.

STOLF, R. Teoria e teste experimental de fórmulas de transformação dos dados de penetrômetro de impacto em resistência do solo. Revista Brasileira de Ciência do Solo, Campinas, v. 15, n. 3, p. 229-235, 1991.
STONE, L. F.; PEREIRA, A. L. Sucessão arroz-feijão irrigados por aspersão: efeitos de espaçamento entre linhas, adubação e cultivar no crescimento, desenvolvimento radicular e consumo d'água do feijoeiro. Pesquisa Agropecuária Brasileira, Brasília, v. 29, n. 6, p. 939-954, jun. 1994.

STONE, L. F.; SILVEIRA, P. M. da. Efeitos do sistema de preparo na compactação do solo, disponibilidade hídrica e comportamento do feijoeiro. Pesquisa Agropecuária Brasileira, Brasília, v. 34, n. 1, p. 83-91, jan. 1999

URCHEI, M. A. Efeitos do plantio direto e do preparo convencional sobre alguns atributos físicos de um Latossolo Vermelho-Escuro argiloso e no crescimento e produtividade do feijoeiro (Phaseolus vulgaris L.) sob irrigação. Botucatu : UNESP, 1996. 150 p. Tese de Doutorado

VIEIRA, M. J.; MUZILLI, O. Características físicas de um Latossolo Vermelho-Escuro sob diferentes sistemas de manejo. Pesquisa Agropecuária Brasileira, Brasília, v. 19, n. 7, p. $873-882$, jul. 1984.

WEAVER, M. L.; NG, H.; BURKE, D. W.; SILBERNAGEL, M. J.; FOSTER, K.; TIMM, H. Effect of soil moisture tension on pod retention and seed yield of beans. HortScience, Alexandria, v. 19, n. 4, p. 567-569, 1984

WEISS, A.; KERR, E. D.; STEADMAN, J. R. Temperature and moisture influences on development of white mold disease (Sclerotinia sclerotiorum) on great northern beans. Plant Disease, St. Paul, v. 64, n. 8. p. 757-759, 1980.

ZAFFARONI, E.; BARROS, H. H. de A.; NÓBREGA, J. A. M.; LACERDA, J. T. de; SOUZA JUNIOR, V. E. de. Efeito de métodos de preparo do solo na produtividade e outras características agronômicas de milho e feijão no Nordeste do Brasil. Revista Brasileira de Ciência do Solo, Campinas, v. 15, n. 1, p. 99-104, 1991 